\begin{tabular}{|c|c|c|}
\hline \multirow{3}{*}{$\begin{array}{r}\text { Case Reports in } \\
\text { Gastroenterology }\end{array}$} & \multirow{2}{*}{\multicolumn{2}{|c|}{ Case Rep Gastroenterol 2015;9:296-301 }} \\
\hline & & \\
\hline & $\begin{array}{l}\text { DOI: 10.1159/000439164 } \\
\text { Publisnea oninee. August 21, } 2015\end{array}$ & $\begin{array}{l}\text { (c) } 2015 \text { The Author(s) } \\
\text { Published by S. Karger AG, Basel } \\
1662-0631 / 15 / 0092-0296 \$ 39.50 / 0 \\
\text { www.karger.com/crg }\end{array}$ \\
\hline & $\begin{array}{l}\text { This article is licensed under the } \\
\text { International License (CC BY-NC) ( } \\
\text { Usage and distribution for commerc }\end{array}$ & $\begin{array}{l}\text { mons Attribution-NonCommercial } 4 . \\
\text { ger.com/Services/OpenAccessLicense } \\
\text { quires written permission. }\end{array}$ \\
\hline
\end{tabular}

\title{
Potential Pitfalls in Transjugular Portosystemic Shunt Placement for Bleeding Rectal Varices
}

\author{
S M Nazmus Sakib ${ }^{a}$ Katsuhiro Kobayashi ${ }^{b} \quad$ Mohammed Jawed $^{b}$ \\ Departments of ${ }^{a}$ Internal Medicine and ${ }^{b}$ Radiology, SUNY Upstate Medical University, \\ Syracuse, N.Y., USA
}

\section{Key Words}

Cirrhosis - Portal hypertension - Anorectal varices - Transjugular intrahepatic portosystemic shunt $\cdot$ Embolization · Liver failure $\cdot$ Hepatic encephalopathy

\begin{abstract}
In patients with portal hypertension, bleeding from rectal varices is rare. However, it can be life-threatening. We report a case of massive bleeding from large rectal varices in a 59 -yearold man with alcoholic cirrhosis. Emergent transjugular intrahepatic portosystemic shunt (TIPS) placement was performed following failed local endoscopic therapy. Despite normalization of the portosystemic pressure gradient, the patient had another episode of massive bleeding on the following day. Embolization of the rectal varices via TIPS successfully stopped the bleeding. After the procedure, rapid decompensation of the cirrhosis led to severe encephalopathy, and death was observed. Although TIPSs have been reported to be useful in controlling bleeding from rectal varices, our case illustrates the potential pitfalls in using this technique in the treatment of rectal variceal bleeding. TIPSs may not be always successful in controlling massive bleeding from large rectal varices, even after normalization of portal hypertension. TIPSs can also be associated with life-threatening complications that may lead to early mortality.

(C) 2015 The Author(s)

Published by S. Karger AG, Basel
\end{abstract}

\section{Introduction}

Rectal varices are not an uncommon manifestation in cirrhosis with portal hypertension [1]. However, serious bleeding from rectal varices is uncommon. Because of its rarity, a standard treatment for bleeding rectal varices has not been established. Several authors 
Sakib et al.: Potential Pitfalls in Transjugular Portosystemic Shunt Placement for Bleeding Rectal Varices

have reported the utility of transjugular intrahepatic portosystemic shunt (TIPS) placement to control such bleeding when local therapy, such as endoscopic sclerotherapy or banding, fails [2-5]. However, we experienced a case of massive bleeding from large rectal varices that could not be controlled by TIPS placement, despite normalization of the portosystemic pressure gradient. Furthermore, we observed rapid decompensation of the cirrhosis that led to severe encephalopathy and death after the TIPS placement. We report this case to highlight and discuss potential pitfalls of TIPS placement when using this technique to treat rectal variceal bleeding.

\section{Case Presentation}

A 59-year-old man with a history of alcoholic cirrhosis was hospitalized at an outside facility for massive hematochezia and fainting. He had no prior history of gastrointestinal hemorrhage or malignancy. He underwent upper endoscopy and tagged red blood cell scan, both of which were negative for active bleeding. A computed tomography of the abdomen was performed and did not reveal the source of the gastrointestinal bleeding; a nodular liver with splenomegaly consistent with liver cirrhosis was seen, and a markedly dilated inferior mesenteric vein was also noted. During his 5-day hospitalization, he had approximately 1015 bloody bowel movements and received a total of 6 units of packed red blood cells and 2 units of fresh frozen plasma.

The patient was then transferred to our institution for further management of his persistent hematochezia. He was alert and oriented, and his vital signs were within normal limits. His admission laboratory tests showed a hemoglobin level of $8.3 \mathrm{~g} / \mathrm{dl}$, a serum ammonia level of $45 \mu \mathrm{g} / \mathrm{dl}$, a total bilirubin level of $2.8 \mathrm{mg} / \mathrm{dl}$ and a Model for End-Stage Liver Disease (MELD) score of 18. A flexible sigmoidoscopy was performed and revealed giant bleeding rectal varices (fig. 1). He was successfully treated with variceal banding and sclerotherapy with ethanolamine. He was then aggressively fluid-resuscitated. Beta-blocker and octreotide drips were started. However, he had another episode of massive hematochezia on the following day, with a decrease in hemoglobin level to $5.0 \mathrm{~g} / \mathrm{dl}$. Therefore, the decision was made to proceed with emergent TIPS placement.

A transjugular portogram showed a markedly dilated inferior mesenteric vein with hepatofugal flow. A TIPS was successfully created with a $10 \times 90 \mathrm{~mm}$ Viatorr stent-graft (Gore \& Associates, Flagstaff, Ariz., USA). This resulted in a decrease in the portosystemic pressure gradient from 12 to $6 \mathrm{~mm}$ Hg. After the TIPS placement, brisk hepatopetal flow through the TIPS was seen on the portogram. Despite the successful normalization of the portosystemic pressure gradient, he had another episode of massive bleeding on the following day. Subsequently, the markedly dilated inferior mesenteric vein was catheterized through the patent TIPS. An angiogram of the superior rectal vein was performed, which showed tortuous large rectal varices with brisk hepatofugal flow (fig. 2). Flow into the internal iliac vein branches was observed, confirming portosystemic shunting. Embolization of the rectal varices was then performed, which necessitated multiple coils, $1 \mathrm{ml}$ of N-butyl cyanoacrylate glue, 5,000 units of thrombin and several sheets of gelfoam (fig. 3). After the procedure, the patient did not have any further bleeding episodes, and the serial hemoglobin levels remained stable. The remaining hospital course was significant for rapid decompensation of cirrhosis, with an increase in the total bilirubin level to $8.7 \mathrm{mg} / \mathrm{dl}$, the ammonia level to $121 \mu \mathrm{g} / \mathrm{dl}$ and the MELD score to 28. Stage III hepatic encephalopathy was noted. Despite maximal medical management, his clinical condition continued to deteriorate. He developed acute hypoxic respiratory failure secondary to multiple causes, including progressive liver 
Sakib et al.: Potential Pitfalls in Transjugular Portosystemic Shunt Placement for Bleeding Rectal Varices

failure. He required mechanical ventilation and became minimally responsive. According to the family's wishes, palliative care was instituted. He died 2 weeks after the TIPS placement.

\section{Discussion}

This case highlights two potential pitfalls of TIPS placement when using this technique in the treatment of rectal variceal bleeding.

First, TIPSs may not be always successful in controlling serious bleeding from rectal varices, despite optimal portosystemic pressure reduction. We observed rebleeding after the TIPS placement despite a $50 \%$ reduction in the pressure gradient, with a final pressure gradient of $6 \mathrm{~mm} \mathrm{Hg}$. Some authors have also reported that a TIPS failed to control bleeding from rectal varices $[6,7]$. Recurrent bleeding from rectal varices after TIPS placement may be related to the large size of the varices. Rectal varices, unlike esophageal varices, are true veins and are likely to have larger diameters. According to Laplace's equation, the tension in the varix wall is proportional to the radius of the vessel for any given transmural pressure [8]. Therefore, larger varices can bleed at a lower portosystemic gradient. In general, it is recommended to decrease the portosystemic pressure gradient to $<12 \mathrm{~mm} \mathrm{Hg}$ in esophageal variceal bleeding [9]. However, this targeted pressure gradient may not be adequate for controlling bleeding from rectal varices. Some authors advocate embolization of the rectal varices at the time of TIPS placement, even if normalization of portal hypertension is achieved $[7,10]$. Given the successful control of bleeding following embolization in our case, concomitant variceal embolization at the time of TIPS placement may be necessary to control massive bleeding, especially when the rectal varices are large.

Second, TIPSs can be associated with life-threatening complications that can possibly lead to early mortality. Since the first application of a TIPS in the treatment of recurrent bleeding from anorectal varices in 1993 [2], a TIPS alone or a TIPS combined with variceal embolization has been reported to be useful in controlling such bleeding without significant morbidity or mortality [2-5, 10]. Favorable long-term outcomes have also been reported [4]. However, TIPSs are inherently associated with risks of procedure-related complications, hepatic encephalopathy and progressive liver failure. Godil and McCracken [11] reported a case of rapid liver function decompensation and encephalopathy following TIPS placement in a 73-year-old woman with rectal variceal bleeding. Although no recurrent bleeding was seen, the patient died 4 weeks after the TIPS procedure. According to the American Association for the Study of Liver Diseases practice guidelines, TIPS is recommended only in the absence of other options for patients with 30-day predicted mortality (MELD $>15-18$ or serum bilirubin $>4.0 \mathrm{mg} / \mathrm{dl}$ ) [9]. Although emergent TIPS placement can be the last resort to control massive bleeding from rectal varices, even in high-risk patients it must be used cautiously because it can lead to life-threatening complications, as seen in our case. Despite its minimally invasive nature, TIPS placement has been associated with a 30-day mortality rate as high as $36 \%$ when it is used to control acute gastroesophageal variceal bleeding [12]. One alternative to TIPS placement in high-risk patients may be the percutaneous embolization of rectal varices via a transhepatic approach. Although reports on the use of this technique for bleeding rectal varices are limited, it could be useful in controlling an initial acute bleeding and in stabilizing a patient without affecting liver function [13]. However, collaterals can redevelop after embolization, and recurrent bleeding requiring repeated intervention has been reported [13]. Some authors have reported several cases of obliteration of bleeding large rectal varices with the use of balloon-occluded antegrade transvenous sclerotherapy with or without coil embolization $[14,15]$. In this technique, a sclerosing agent, such as eth- 
Sakib et al.: Potential Pitfalls in Transjugular Portosystemic Shunt Placement for Bleeding Rectal Varices

anolamine oleate, was injected into the varices while the superior rectal vein was occluded using a balloon catheter. The initial results were encouraging. Further research is needed to determine its efficacy.

In conclusion, although TIPSs have been reported to be useful in controlling bleeding from rectal varices, there are potential pitfalls in using this technique to treat rectal variceal bleeding. A TIPS may not always be successful in controlling massive bleeding from large rectal varices even after normalization of portal hypertension, and concomitant variceal embolization may be necessary. Furthermore, TIPSs can be associated with life-threatening complications that may lead to early mortality.

\section{References}

1 Chawla Y, Dilawari JB: Anorectal varices - their frequency in cirrhotic and non-cirrhotic portal hypertension. Gut 1991;32:309-311.

-2 Katz JA, Rubin RA, Cope C, Holland G, Brass CA: Recurrent bleeding from anorectal varices: successful treatment with a transjugular intrahepatic portosystemic shunt. Am J Gastroenterol 1993;88:1104-1107.

3 Shibata D, Brophy DP, Gordon FD, Anastopoulos HT, Sentovich SM, Bleday R: Transjugular intrahepatic portosystemic shunt for treatment of bleeding ectopic varices with portal hypertension. Dis Colon Rectum 1999;42:1581-1585.

-4 Ory G, Spahr L, Megevand JM, Becker C, Hadengue A: The long-term efficacy of the intrahepatic portosystemic shunt (TIPS) for the treatment of bleeding anorectal varices in cirrhosis. A case report and review of the literature. Digestion 2001;64:261-264.

5 Kochar N, Tripathi D, McAvoy NC, Ireland H, Redhead DN, Hayes PC: Bleeding ectopic varices in cirrhosis: the role of transjugular intrahepatic portosystemic stent shunts. Aliment Pharmacol Ther 2008;28:294-303.

6 Demirel H, Pieterman H, Lameris JS, van Buuren HR: Transjugular embolization of the inferior mesenteric vein for bleeding anorectal varices after unsuccessful transjugular intrahepatic portosystemic shunt. Am J Gastroenterol 1997;92:1226-1227.

-7 Vangeli M, Patch D, Terreni N, Tibballs J, Watkinson A, Davies N, Burroughs AK: Bleeding ectopic varices treatment with transjugular intrahepatic porto-systemic shunt (TIPS) and embolisation. J Hepatol 2004;41: 560-566.

8 Miller LS, Kim JK, Dai Q, Mekapati J, Izanec J, Chung C, Liu JB, Sanderson A, Bohning M, Desipio J, Gandegok J, Harberson JJ, Schneck C, Nicosia MA, Thangada V, Thomas B, Copeland B, Miller E, Miller A, Ahmed N, Brasseur JG: Mechanics and hemodynamics of esophageal varices during peristaltic contraction. Am J Physiol Gastrointest Liver Physiol 2004;287:G830-G835.

-9 Boyer TD, Haskal ZJ; American Association for the Study of Liver Diseases: The role of transjugular intrahepatic portosystemic shunt (TIPS) in the management of portal hypertension: update 2009. Hepatology 2010;51:306.

10 Hidajat N, Stobbe H, Hosten N, Schroeder RJ, Fauth M, Vogl T, Felix R: Transjugular intrahepatic portosystemic shunt and transjugular embolization of bleeding rectal varices in portal hypertension. AJR Am J Roentgenol 2002;178:362-363.

11 Godil A, McCracken JD: Rectal variceal bleeding treated by transjugular intrahepatic portosystemic shunt. Potentials and pitfalls. J Clin Gastroenterol 1997;25:460-462.

-12 Sanyal AJ, Freedman AM, Luketic VA, Purdum PP, Shiffman ML, Tisnado J, Cole PE: Transjugular intrahepatic portosystemic shunts for patients with active variceal hemorrhage unresponsive to sclerotherapy. Gastroenterology 1996;111:138-146.

13 Macedo TA, Andrews JC, Kamath PS: Ectopic varices in the gastrointestinal tract: short- and long-term outcomes of percutaneous therapy. Cardiovasc Intervent Radiol 2005;28:178-184.

14 Okazaki H, Higuchi K, Shiba M, Nakamura S, Wada T, Yamamori K, Machida A, Kadouchi K, Tamori A, Tominaga K, Watanabe T, Fujiwara Y, Nakamura K, Arakawa T: Successful treatment of giant rectal varices by modified percutaneous transhepatic obliteration with sclerosant: report of a case. World J Gastroenterol 2006;12:5408-5411.

15 Minamiguchi H, Kawai N, Sato M, Ikoma A, Sanda H, Nakata K, Tanaka T, Nakai M, Sonomura T: Successful treatment of endoscopically unmanageable rectal varices by balloon-occluded antegrade transvenous sclerotherapy followed by microcoil embolization. J Vasc Interv Radiol 2013;24:1399-1403. 


\begin{tabular}{|c|c|c|}
\hline \multirow{2}{*}{$\begin{array}{l}\text { Case Reports in } \\
\text { Gastroenterology }\end{array}$} & \multicolumn{2}{|c|}{ Case Rep Gastroenterol 2015;9:296-301 } \\
\hline & DOI: $10.1159 / 000439164$ & $\begin{array}{l}\text { (c) } 2015 \text { The Author(s). Published by S. Karger AG, Basel } \\
\text { www.karger.com/crg }\end{array}$ \\
\hline
\end{tabular}

Sakib et al.: Potential Pitfalls in Transjugular Portosystemic Shunt Placement for Bleeding Rectal Varices

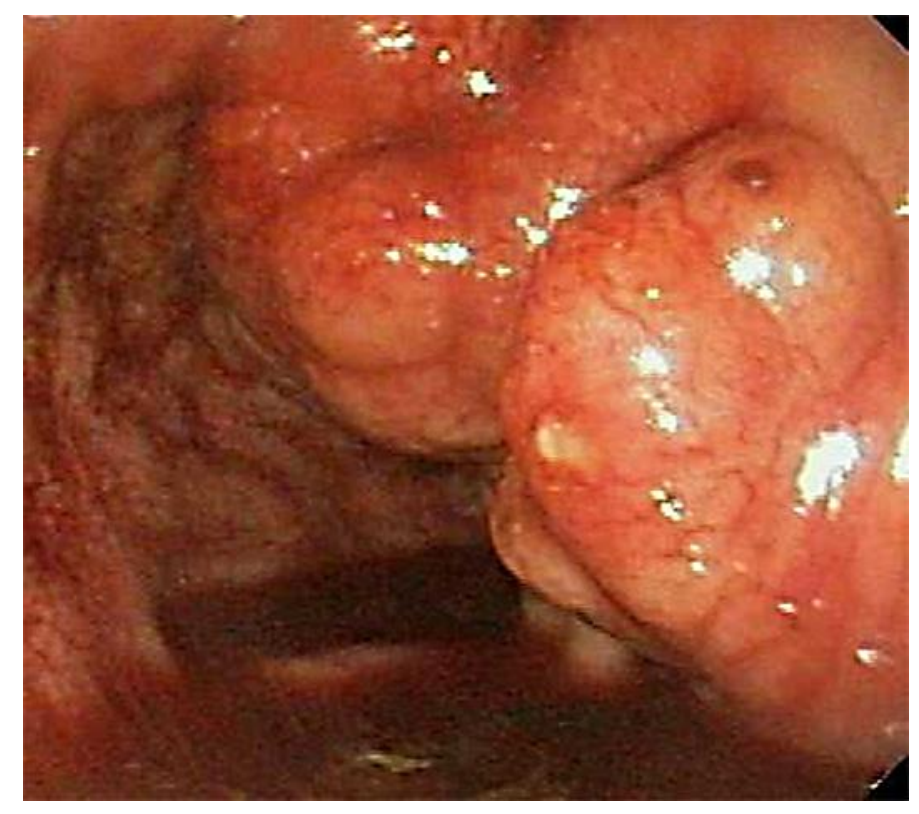

Fig. 1. Upper endoscopy picture showing bleeding giant varices in the rectum.

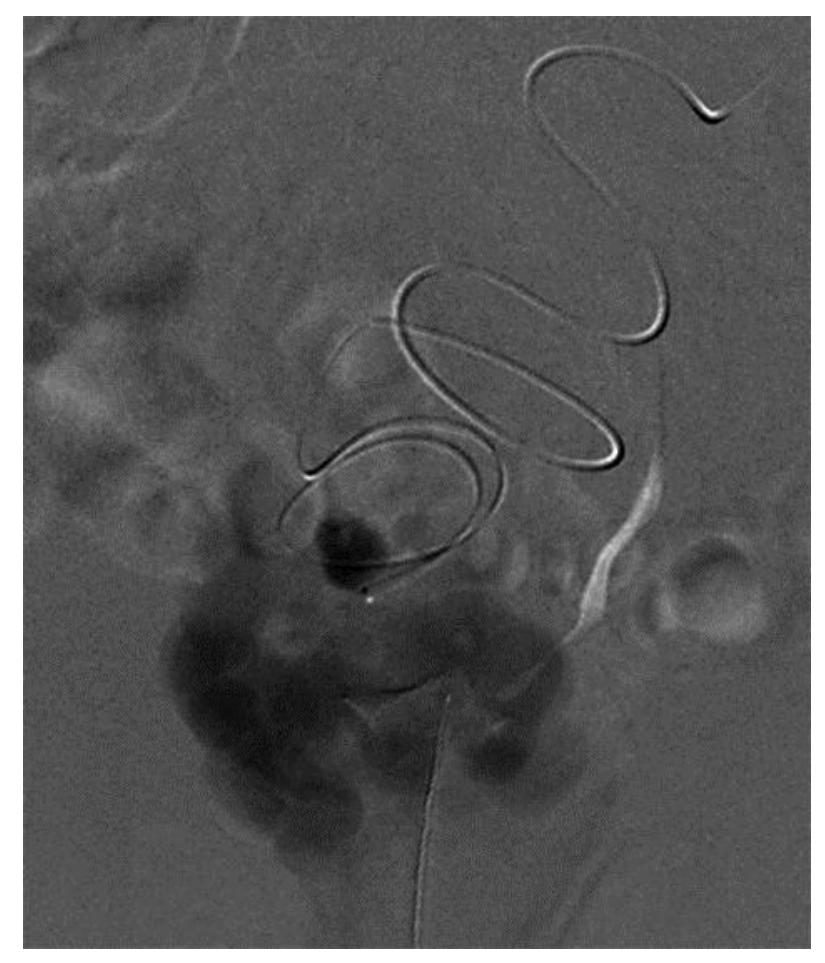

Fig. 2. Superior rectal venogram obtained through a microcatheter showing tortuous giant rectal varices with hepatofugal flow. 
Sakib et al.: Potential Pitfalls in Transjugular Portosystemic Shunt Placement for Bleeding Rectal Varices

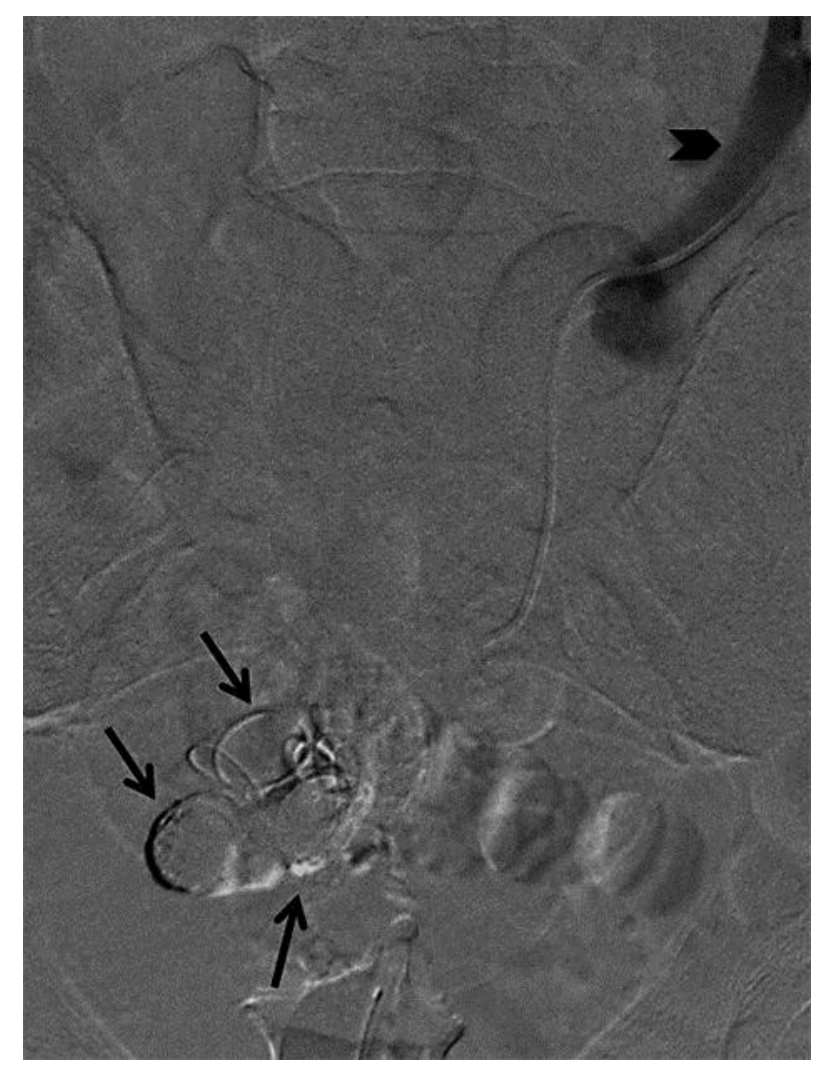

Fig. 3. Superior rectal venogram obtained after embolization of the rectal varices with multiple coils (arrows), N-butyl cyanoacrylate glue, thrombin and gelfoam. Note that no rectal varices were visualized. Hepatopetal flow within the superior rectal vein is noted (arrowhead). 